\title{
JPE 12-3-8
}

\section{A Carrier-Based Pulse Width Modulation Method for Indirect Matrix Converters}

\author{
Dinh-Tuyen Nguyen*, Hong-Hee Lee ${ }^{\dagger}$, and Tae-Won Chun* \\ ${ }^{*}$ School of Electrical Engineering, University of Ulsan, Ulsan, Korea
}

\begin{abstract}
This paper proposes a carrier-based pulse width modulation (PWM) method to control an indirect matrix converter (IMC) by analyzing the relationship between the space vector PWM (SVPWM) and the carrier-based PWM. The complexity of the SVPWM method for an IMC can be reduced by using an equivalent carrier-based PWM method. The advantage of the proposed algorithm is its ability use only one symmetrical triangular carrier signal to generate the gate signals for all of the power switches in both the rectifier and inverter stages as compared to the conventional method where the carrier signal used in the rectifier stage is different from that of the inverter stage. In addition, by using a suitable offset voltage component in the modulation signals, the output voltage magnitude reaches 0.866 of the input voltage magnitude. Simulation and experimental results are provided in order to validate the proposed method.
\end{abstract}

Key words: AC/AC converter, Carrier-based PWM, Indirect matrix converter, Space vector PWM

\section{INTRODUCTION}

Matrix converters (MCs) were first mentioned in the early 1980's by Alesina and Venturini [1]. In recent years, these converters have become more attractive because of the evolution of power device technologies and the development of large power integrated circuits. MCs are devices used for converting directly from $\mathrm{AC}$ power to $\mathrm{AC}$ power without any intermediate energy storage component. These topologies have some advantages such as high quality input/output current waveforms, a controllable input power factor, operation in all four quadrants of the torque-speed and a long life-time due to the absence of bulky electrolytic capacitors as compared to back-to-back converters.

MCs have two kinds of topologies: direct matrix converters (DMC) and indirect matrix converters (IMC) [2]. As shown in Fig. 1, a three-phase DMC includes nine bidirectional switches [3], [4]. The IMC has two stages: the rectifier and the inverter stages, as shown in Fig. 2 [5]. DMC and IMC have the same number power switches and they are able to generate input/output waveforms with the same performance.

Manuscript received Sep. 23, 2011; revised Feb. 20, 2012 Recommended for publication by Associate Editor Yong-Sug Suh.

${ }^{\dagger}$ Corresponding Author: hhlee@mail.ulsan.ac.kr

Tel: +82-52-259-2187, Fax: +82-52-259-2186, Univ. of Ulsan

${ }^{*}$ School of Electrical Engineering, University of Ulsan, Korea

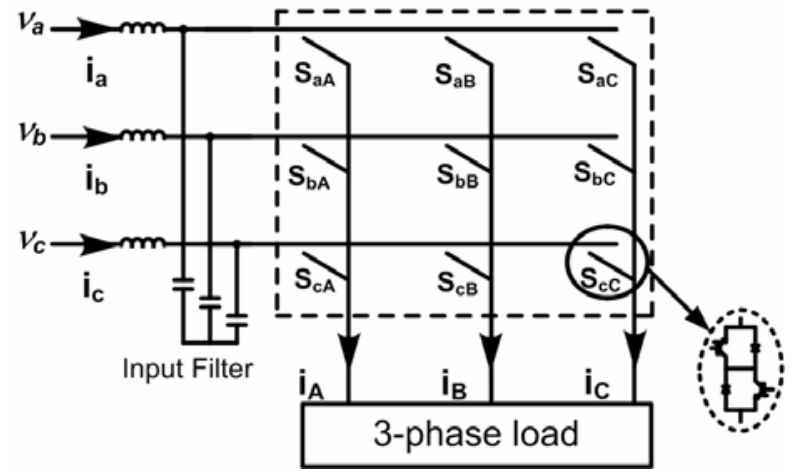

Fig. 1. DMC topology.

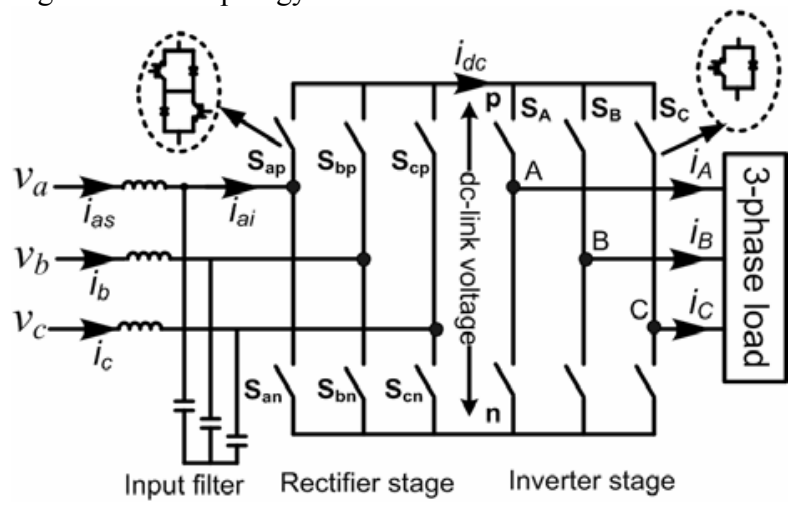

Fig. 2. IMC topology. 
However, the IMC has recently received more consideration because it has shown several advantages such as a simpler commutation, the possibility of reducing the required number of power switches and the possibility of modifying the topology. Up to now, many researchers have been interested in the development of IMC, and there are many research publications which focus on the development of the IMC topology. A novel sparse matrix converter topology with a reduced number of power switches in the rectifier stage is proposed in [6]. The possibility of constructing the IMC topology with a dual-output for multiple drive system applications is presented in [7], [8]. A hybrid IMC is proposed in [9] to increase the maximum transfer voltage ratio from 0.866 to 1 .

On the other hand, some papers have concentrated on the modulation technology for MCs' control [10]-[19]. Generally, the modulation strategies have been developed based on space vectors. The SVPWM method for the IMC was originally introduced in [20]. Another study on SVPWM with a reduced common mode voltage was presented in [21]. From these results, the sinusoidal waveforms of the input current/output voltage and the maximum voltage transfer ratio of the IMC are obtained with the SVPWM method. However, the SVPWM approach has some disadvantages. It needs complex calculations and tables to synthesize the reference input current and the reference output voltage. Therefore, recently, a carrier-based PWM method has been considered for the control of the IMC in order to overcome the drawback of the SVPWM method. In the carrier-based PWM method, the high frequency triangular carrier is compared with the modulation signals to create the gating pulses for the switches in the power circuit.

Carrier-based PWM techniques for the IMC have been proposed in [22], [23]. However, the carrier signal used for the rectifier stage is different from that of the inverter stage. The carrier signal used for the rectifier stage is a symmetrical triangular signal, while the carrier signal used for the inverter stage is an unsymmetrical triangular signal. Furthermore, the slopes of the rising and falling edges of the unsymmetrical carrier signal change in every sampling period due to the variation of the dc-link voltage. These slopes depend on the duty cycles of the active vectors in the rectifier stage control.

In order to overcome the limitation of the conventional carrier-based PWM method, which is presented in [22], [23], this paper presents a novel carrier-based PWM method to control the IMC. When compared to the conventional method, the proposed method uses only one symmetrical triangular signal with a fixed slope rising and falling to control both the rectifier and the inverter stage. The proposed scheme can be implemented easily by using only one up/down counter, which is available in most digital signal processors (DSP). When compared to the conventional SVPWM, which takes a long time to determine the duty cycle of the effective vectors and to make the switching pattern according to the position of the reference output voltage vector and the reference input current vector, the proposed method demands less computational complexity for DSP. Nevertheless, the proposed carrier-based PWM method does not provide the CMV reduction when compared to the reduced CMV-PWM method introduced in [21] because it is based on the conventional SVPWM method, which is presented in [18]-[20].

This paper is organized as follows. The operation principle and the space vector analysis of the IMC are described in section II. The proposed carrier-based PWM method is presented in section III. The simulation and the experimental results are provided in section IV and section $\mathrm{V}$, respectively. Some conclusions are given in the last section.

\section{THE OPERATION PRINCIPLE AND SPACE VECTOR ANALYSIS OF THE IMC}

In this section, the operation principle and the space vector analysis of the IMC are presented. The IMC topology consists of two stages as shown in Fig. 2. The rectifier stage, which is composed of six bidirectional switches, is directly connected to an inverter stage. The arrangement of the power switches in the inverter stage is the same as that of a conventional two-level voltage source inverter. The function of the rectifier stage is to maintain the maximum positive voltage in the dc-link as well as to maintain the sinusoidal waveform in the input currents. Output voltages with a variable frequency and amplitude can be synthesized by the inverter stage control. The basic control strategy for the IMC is based on a space vector analysis of the input current and output voltage.

As shown in Fig. 2, the voltage and current at the input side of the IMC are denoted by $a, b$ and $c$ while those of the output side are denoted by $A, B$ and $C$. It is assumed that the IMC is connected to a balanced three-phase power supply, which is given as follows:

$$
\begin{gathered}
v_{a}=V_{1} \cos \left(\omega_{1} t+\varphi_{1}\right) \\
v_{b}=V_{1} \cos \left(\omega_{1} t+\varphi_{1}-2 \pi / 3\right) \\
v_{c}=V_{1} \cos \left(\omega_{1} t+\varphi_{1}-4 \pi / 3\right)
\end{gathered}
$$

The desired three-phase output voltages are described by:

$$
\begin{gathered}
v_{A}=V_{2} \cos \left(\omega_{2} t+\varphi_{2}\right) \\
v_{B}=V_{2} \cos \left(\omega_{2} t+\varphi_{2}-2 \pi / 3\right) \\
v_{C}=V_{2} \cos \left(\omega_{2} t+\varphi_{2}-4 \pi / 3\right)
\end{gathered}
$$

where, $V_{I}$ and $V_{2}$ are the amplitude of the input and output phase voltages, respectively.

$\omega_{1}$ and $\omega_{2}$ are the input and output angular frequencies, respectively.

$\varphi_{1}$ and $\varphi_{2}$ are the initial phase angle of the input and output 
TABLE I

Modulated Switches and Duty Cycles of Active Vector According to The InPut current Sector

\begin{tabular}{|c|c|c|c|c|c|c|c|c|}
\hline \multirow{3}{*}{$\begin{array}{c}\text { Input } \\
\text { sector }\end{array}$} & \multirow{3}{*}{$\begin{array}{c}\omega_{1} \mathrm{t}+\varphi_{1} \\
-\pi / 6 \ldots \pi / 6\end{array}$} & \multirow{3}{*}{$\begin{array}{c}\text { ON } \\
\text { switch }\end{array}$} & \multirow{2}{*}{\multicolumn{2}{|c|}{$\begin{array}{c}\text { Modulated } \\
\text { switches }\end{array}$}} & \multicolumn{2}{|c|}{ Duty ratio } & \multirow{2}{*}{\multicolumn{2}{|c|}{$\begin{array}{c}\text { dc-link voltage } \\
\left(\mathrm{V}_{\mathrm{dc}}\right)\end{array}$}} \\
\hline & & & & & \multirow{2}{*}{$\begin{array}{r}d_{x} \\
-v_{c} / v_{a} \\
\end{array}$} & \multirow{2}{*}{$\begin{array}{r}d_{y} \\
-v_{b} / v_{a}\end{array}$} & & \\
\hline & & & $S_{c n}$ & $S_{b n}$ & & & $v_{a c}$ & $v_{a b}$ \\
\hline 2 & $\pi / 6 . . \pi / 2$ & $S_{c n}$ & $S_{a p}$ & $S_{b p}$ & $-v_{a} / v_{c}$ & $-v_{b} / v_{c}$ & $v_{a c}$ & $v_{b c}$ \\
\hline 3 & $\pi / 2 \ldots 5 \pi / 6$ & $S_{b p}$ & $S_{a n}$ & $S_{c n}$ & $-v_{a} / v_{b}$ & $-v_{c} / v_{b}$ & $v_{b a}$ & $v_{b c}$ \\
\hline 4 & $5 \pi / 6 . .7 \pi / 6$ & $S_{a n}$ & $S_{b p}$ & $S_{c p}$ & $-v_{b} / v_{a}$ & $-v_{c} / v_{a}$ & $v_{b a}$ & $v_{c a}$ \\
\hline 5 & $7 \pi / 6 . .9 \pi / 6$ & $S_{c p}$ & $S_{b n}$ & $S_{a n}$ & $-v_{b} / v_{c}$ & $-v_{a} / v_{c}$ & $v_{c b}$ & $v_{c a}$ \\
\hline 6 & $9 \pi / 6 . .11 \pi / 6$ & $S_{b n}$ & $S_{a p}$ & $S_{c p}$ & $-v_{a} / v_{b}$ & $-v_{c} / v_{b}$ & $v_{a b}$ & $v_{c b}$ \\
\hline
\end{tabular}

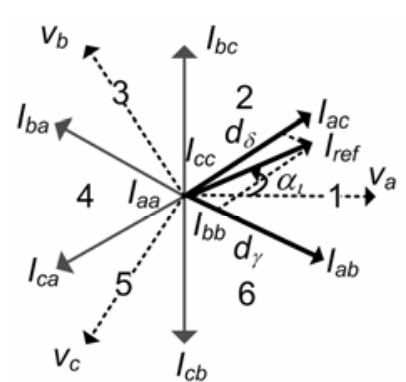

(a)

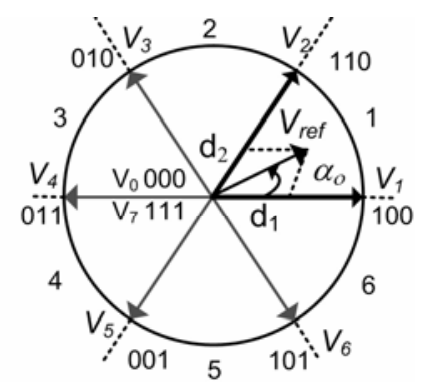

(b)
Fig. 3. (a) The diagram space vector of the rectifier stage (b) The diagram space vector of the inverter stage.

phase voltages, respectively.

For the sake of explaining the modulation technique of the IMC, it is assumed that both the reference input current and the reference output voltage vectors are located in sector 1 $\left(-\pi / 6 \leq \alpha_{i} \leq \pi / 6\right.$ and $\left.0 \leq \alpha_{o} \leq \pi / 3\right)$ without missing the generality of the analysis, where $\alpha_{\mathrm{i}}$ and $\alpha_{\mathrm{o}}$ are the angles within their respective sectors of the input current and the output voltage reference vectors.

\section{A. Rectifier stage}

The space vector diagram of the rectifier stage includes six active current vectors and three zero current vectors as shown in Fig. 3(a). Each current vector expresses the connection of input phase voltages to the dc-link bus. For example, the vector $I_{a b}$ represents the connection of the input voltage phase $a$ to the positive terminal ( $p$ ) and the input voltage phase $b$ to the negative terminal $(n)$ of the dc-link bus. If it is assumed that the reference input current vector $I_{\text {ref }}$ is located in sector 1, it can be synthesized by using the two active vectors $I_{a b}$ and $I_{a c}$. The duty cycles of the two active current vectors $I_{a b}$ and $I_{a c}$ are determined as follows:

$$
d_{\gamma}=m_{i} \sin \left(\pi / 6-\alpha_{i}\right)
$$

$$
d_{\delta}=m_{i} \sin \left(\alpha_{i}+\pi / 6\right)
$$

where $m_{i}$ is the modulation index in the rectifier stage control.

In the rectifier stage, the zero vectors are eliminated because they are redundant with the inverter stage. Therefore, only positive line-to-line input voltages exist in the dc-link bus. In order to complete one sampling period, the duty cycles of the two active current vectors are recalculated as follows:

$$
\begin{aligned}
& d_{x}=\frac{d_{\delta}}{d_{\delta}+d_{\gamma}}=-\frac{v_{c}}{v_{a}} \\
& d_{y}=\frac{d_{\gamma}}{d_{\delta}+d_{\gamma}}=-\frac{v_{b}}{v_{a}}
\end{aligned}
$$

By a similar analysis, the modulated switches and the duty cycles of the active vectors in all six of the input sectors are summarized in Table I.

In one sampling period, the dc-link voltage has two values $v_{a b}$ and $v_{a c}$ with the duty cycles $d_{x}$ and $d_{y}$, respectively Therefore, the local average value of the dc-link voltage is determined by:

$$
\bar{V}_{d c}=d_{x} v_{a c}+d_{y} v_{a b}=\frac{3}{2} \frac{V_{1}}{\cos \left(\omega_{1} t+\varphi_{1}\right)}
$$

The minimum value of $\bar{V}_{d c}$ is:

$$
\bar{V}_{d c(\min )}=\frac{3}{2} V_{1}
$$

The average of the dc-link voltage is used to calculate the duty cycles of the active and zero vectors in the inverter stage.

\section{B. Inverter stage}

Once the switching states of the rectifier stage have been decided, the traditional SVPWM is applied to control the inverter stage. For calculating the duty cycles of the active and zero vectors in the inverter stage, it is necessary to refer to the local average dc-link voltage. The eight space vectors, including the six active vectors $\left(V_{1} \sim V_{6}\right)$ and the two zero vectors $\left(V_{0}, V_{7}\right)$, are used in the SVPWM method. According 
to the sampled reference voltage vector $V_{\text {ref }}$ and the angle $\alpha_{o}$ in sector 1, as shown in Fig. 3(b), the two active vector $\left(V_{1}, V_{2}\right)$ and the two zero vectors $\left(V_{0}, V_{7}\right)$ are used to synthesize the reference output voltage vector. In one sampling period $T_{s}$, the two active vectors $V_{1}$ and $V_{2}$ are applied during the times $T_{1}$ and $T_{2}$, respectively. Meanwhile, the zero vectors are applied during the times $T_{s}-T_{1}-T_{2}$. The application time of the two active and the two zero vectors are determined as follows:

$$
\begin{gathered}
T_{1}=d_{1} T_{s}=\sqrt{3} \frac{\left|\vec{V}_{r e f}\right|}{\bar{V}_{d c}} \sin \left(\pi / 3-\alpha_{o}\right) T_{s} \\
T_{2}=d_{2} T_{s}=\sqrt{3} \frac{\left|\vec{V}_{r e f}\right|}{\bar{V}_{d c}} \sin \left(\alpha_{o}\right) T_{s} \\
T_{0}+T_{7}=T_{s}-T_{1}-T_{2}
\end{gathered}
$$

where, $d_{1}$ and $d_{2}$ are the duty cycles of the vector $V_{1}$ and $V_{2}$, respectively. $\vec{V}_{r e f}$ is the reference output voltage vector, which can be described by $\vec{V}_{r e f}=V_{2} e^{j \alpha_{o}}$.

The distribution of the two zero vectors $V_{0}$ and $V_{7}$ influences the output voltage performance. The analysis results from [24], [25] show that the balanced distribution of the two zero vectors is superior due to the low harmonics distortion characteristic. Therefore, the application time of the two zero vectors can be written as:

$$
T_{0}=T_{7}=\frac{1}{2}\left(T_{s}-T_{1}-T_{2}\right)
$$

To obtain the balanced input currents and output voltages, the switching pattern should produce effective combinations for the rectifier and the inverter switching states. As in the above analysis, in one sampling period $T_{s}$, the dc-link voltage has two values $v_{a b}$ and $v_{a c}$ with the times $d_{x} T_{s}$ and $d_{y} T_{s}$, respectively. Therefore, the switching states at the inverter stage should be divided into two groups. The application time of the two active and the two zero vectors in each group is calculated as follows:

$$
\begin{aligned}
& T_{1(x)}=T_{1} d_{x} ; T_{2(x)}=T_{2} d_{x} ; T_{0(x)}=T_{0} d_{x} ; T_{7(x)}=T_{7} d_{x} \\
& T_{1(y)}=T_{1} d_{y} ; T_{2(y)}=T_{2} d_{y} ; T_{0(y)}=T_{0} d_{y} ; T_{7(y)}=T_{7} d_{y}
\end{aligned}
$$

\section{Switching patterns for safe commutation}

In order to ensure the zero dc-link current commutation in the rectifier stage, the inverter stage should work in the zero vectors when the rectifier stage is commutating. Therefore, all of the currents in the rectifier stage are zero during the commutation time. It results in a reduction in the power switching loss in rectifier stage and the complex multi-step commutation is avoided. According to the principle of selecting the zero vectors in the inverter stage, the switching pattern is arranged as shown in Fig. 4, when both the rectifier and inverter stage are operated in sector 1 [18]-[20]. It can be seen that the state transitions of the active switches $\left(S_{b n}, S_{c n}\right)$

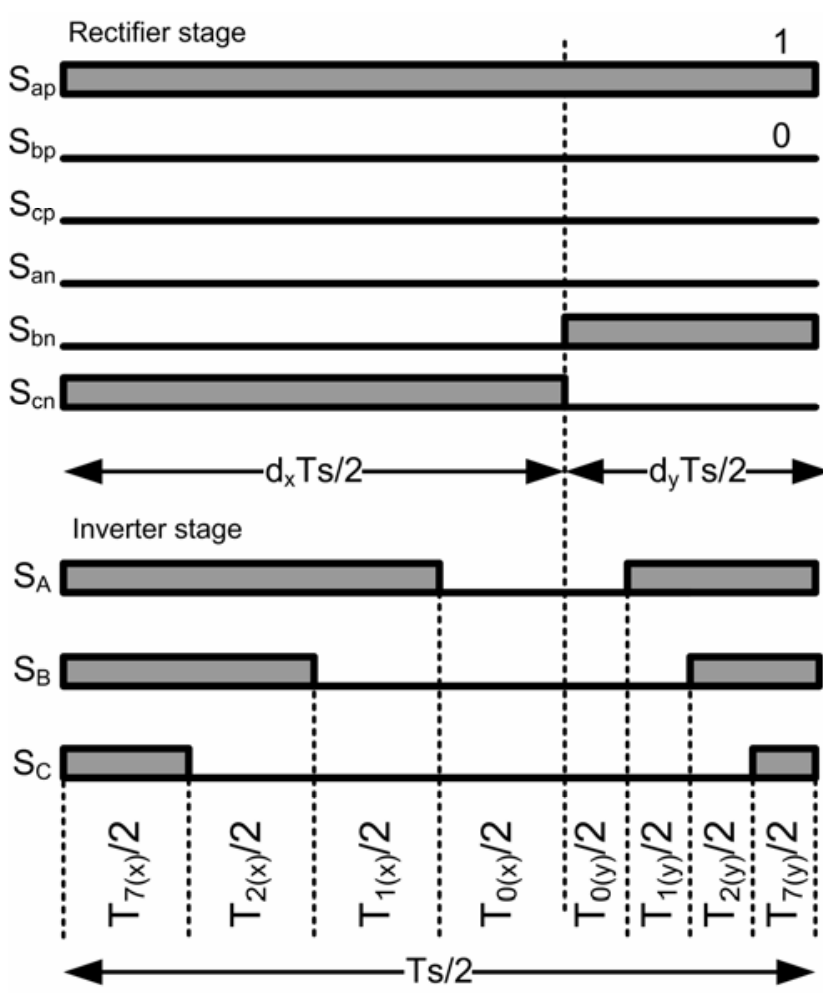

Fig. 4. The coordination between switching states of the rectifier and inverter stages.

in rectifier stage occur during the time where the zero vectors are applied in the inverter stage. Fig. 4 shows the switching states and the timing of all the switches during half of a sampling period $(T S / 2)$.

\section{PROPOSED CARRIER-BASED PWM TECHNIQUE}

From the above analysis, the implementation of the conventional PWM strategy for the IMC is complex. First, the selection of the effective vectors in the two stages is implemented independently, and the duty ratios of the effective vectors in the rectifier and inverter stage are determined by calculating some equations. Then, the switching states of the rectifier and the inverter stage are coordinated in order to achieve balanced output voltages and zero current commutation at the rectifier stage. In order to overcome this problem, the gating signals in the proposed method are easily made by the carrier-based PWM method.

A carrier-based PWM modulator is comprised of modulation signals and a carrier signal. The PWM signals are generated by comparing the modulation signals with a symmetrical triangular carrier signal. The frequency of the carrier signal is much higher than that of the modulation signals. To correlate the carrier-based PWM with the SVPWM, it has to find a set of modulation signals, which 

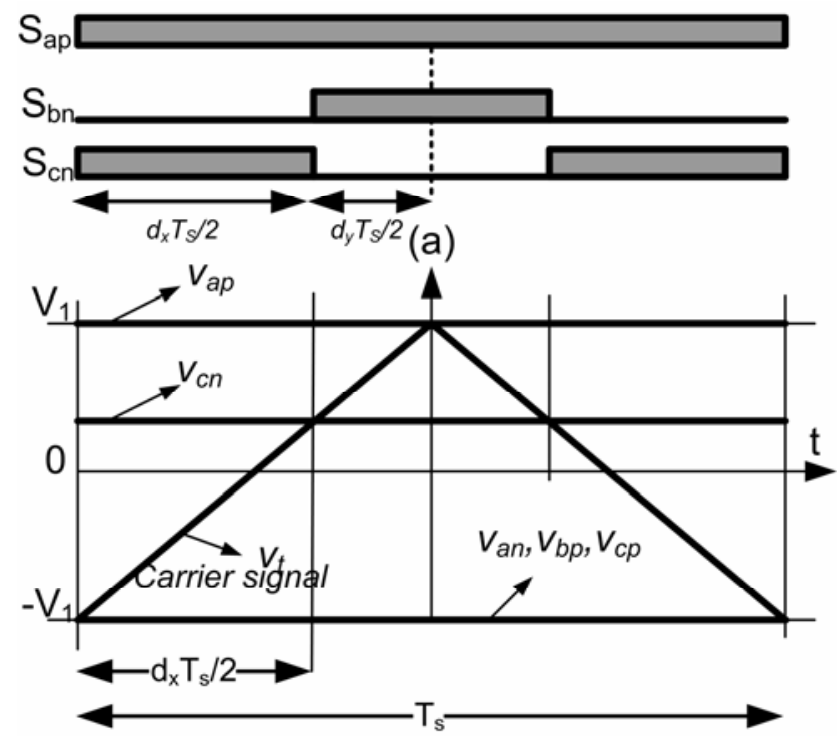

(b)

Fig. 5. (a) The timing of modulated switches. (b) Carrier-based PWM technique for rectifier stage in sector 1.

when compared with the carrier signal produce the same PWM signals as the SVPWM technique. The implementations of the carrier-based PWM technique for the rectifier and inverter stages are independent.

\section{A. Rectifier stage}

Assume that the reference input current vector is located in sector 1, as shown in Fig. 3(a). The application time of the upper switch of phase $a\left(S_{a p}\right)$ and the two lower switches of phases $b$ and $c\left(S_{b n}\right.$ and $\left.S_{c n}\right)$ are shown in Fig. 5(a). In a half sampling period $T_{s} / 2$, the application time of the switch $S_{a p}$ is $T_{s} / 2$ and the application time of the switch $S_{c n}$ is $d_{x} T_{s} / 2$. Fig. 5(b) shows the intersection of the modulation signals and the carrier signal, which make the gate signals for the switches $S_{a p}$ and $S_{c n}$.

The symmetrical triangular carrier signal, which is shown in Fig. 5(b), can be described by:

$$
v_{t}=\left(\frac{4}{T_{s}} t-1\right) V_{1}
$$

where, $v_{t}$ and $V_{l}$ are the instantaneous and the peak values of the carrier signal, respectively.

The modulation signals, which are used to generate the gate signals for all six of the bidirectional switches in the rectifier stage, are given as follows:

$$
\begin{gathered}
v_{a p}=V_{1} \\
v_{c n}=\left(2 d_{x}-1\right) V_{1} \\
v_{b p}=-V_{1} ; v_{c p}=-V_{1} ; v_{a n}=-V_{1}
\end{gathered}
$$

The gate signal for the switch $S_{b n}$ is complementary to that of the switch $S_{c n}$.

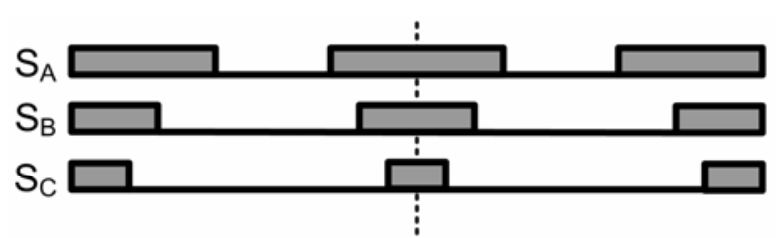

(a)

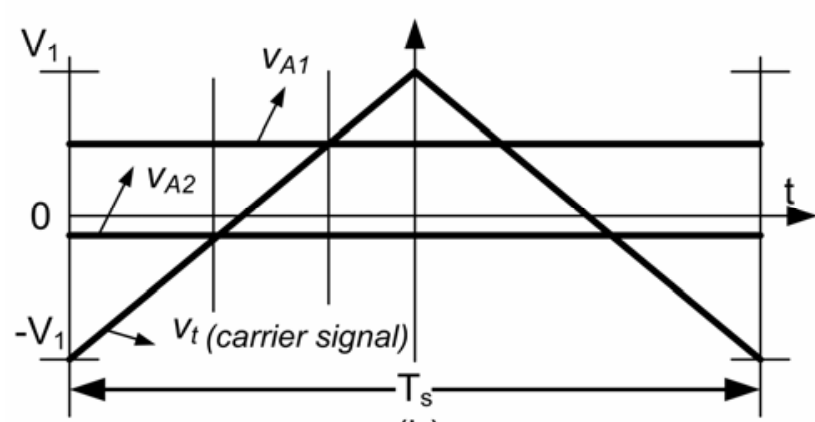

(b)

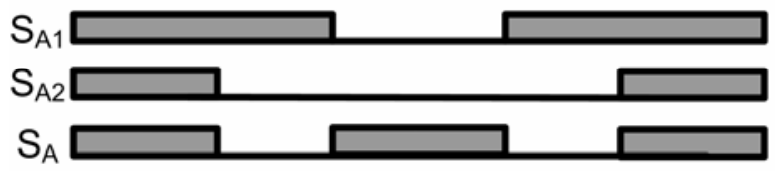

(c)

Fig. 6. (a) The switching state of three upper switches in the inverter stage. (b) The waveform of modulation signals and carrier signal. (c) The generation of gate signal for the switch $\mathrm{S}_{\mathrm{A}}$.

\section{B. Inverter stage}

Fig. 6(a) illustrates the switching pattern of the inverter stage when the reference output voltage vector is located in sector 1 . It can be seen that the inverter switching frequency is twice the carrier signal frequency. Therefore, to generate the gate signal for each of the switches in the inverter stage, two modulation signals are needed. For example, to generate the gate signal for the upper switch of phase A $\left(S_{A}\right)$, the two modulation signals $v_{A 1}$ and $v_{A 2}$ are needed. The waveforms of the modulation signals $v_{A 1}$ and $v_{A 2}$ and the carrier signal $v_{t}$ are shown in Fig. 6(b). The pulses $S_{A I}$ and $S_{A 2}$ are obtained from a comparison of the two modulation signals $v_{A I}$ and $v_{A 2}$ with a symmetrical triangular signal, respectively. Thus, the gate signal for the switch $S_{A}$ is determined by using the XNOR function, as shown in Fig. 6(c).

$$
S_{A}=S_{A 1} \cdot S_{A 2}+\bar{S}_{A 1} \cdot \bar{S}_{A 2}
$$

By substituting the application time of the zero vectors and the active vectors from (13) and (14) into (15), the two modulation signals $v_{A 1}$ and $v_{A 2}$ are obtained as follows:

$$
\begin{aligned}
& v_{A 1}=V_{1}\left(-2 d_{y} \frac{v_{A}+v_{\text {offset }}}{\bar{V}_{d c}}+d_{x}\right) \\
& v_{A 2}=V_{1}\left(2 d_{x} \frac{v_{A}+v_{o f f s e t}}{\bar{V}_{d c}}-d_{y}\right)
\end{aligned}
$$

By a similar calculation, the couple of the modulation 


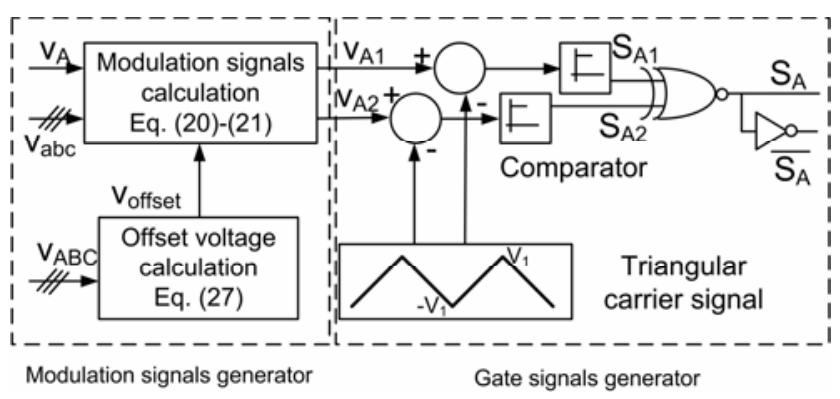

Fig. 7. The block diagram of the carrier-based PWM generator.

signals to generate the gate signal for the switches $S_{B}$ and $S_{C}$ are determined by:

$$
\begin{aligned}
& v_{B 1}=V_{1}\left(-2 d_{y} \frac{v_{B}+v_{\text {offset }}}{\bar{V}_{d c}}+d_{x}\right) \\
& v_{B 2}=V_{1}\left(2 d_{x} \frac{v_{B}+v_{\text {offset }}}{\bar{V}_{d c}}-d_{y}\right) \\
& v_{C 1}=V_{1}\left(-2 d_{y} \frac{v_{C}+v_{\text {offset }}}{\bar{V}_{d c}}+d_{x}\right) \\
& v_{C 2}=V_{1}\left(2 d_{x} \frac{v_{C}+v_{o f f s e t}}{\bar{V}_{d c}}-d_{y}\right)
\end{aligned}
$$

where $v_{\text {offset }}$ is the offset voltage, which can be written as:

$$
v_{\text {offset }}=-0.5 v_{A}-0.5 v_{C}
$$

Equations (20)-(26) are obtained when the reference output voltage vector is located in sector 1 . Generally, when the offset voltage is chosen as (27), these equations are valid when the reference output voltage vector is located in the other sectors.

$$
v_{\text {offset }}=-\frac{1}{2}\left(v_{\max }+v_{\min }\right)
$$

where $v_{\max }=\max \left(v_{A}, v_{B}, v_{C}\right)$ and $v_{\min }=\min \left(v_{A}, v_{B}, v_{C}\right)$

The offset voltage component chosen as (27) leads the maximum modulation index in the inverter stage which is $2 / \sqrt{3}$. Therefore, the maximum voltage transfer ratio of the IMC with the proposed carrier-based PWM method can be derived as:

$$
q_{\max }=\frac{V_{2(\max )}}{V_{1}}=\frac{2}{\sqrt{3}} \frac{\bar{V}_{d c(\min )}}{2} \frac{1}{V_{1}}=\frac{\sqrt{3}}{2}
$$

Fig. 7 shows a block diagram of the carrier-based PWM generator for the inverter stage. In the proposed carrier-based PWM generator, two separated function blocks named "modulation signals generator" and "gate signals generator" are implemented to control the inverter stage of the IMC. All of the required operations are easily executed without any look-up table or complex calculations. In addition, there is no need to coordinate the switching state of the rectifier and inverter stages.

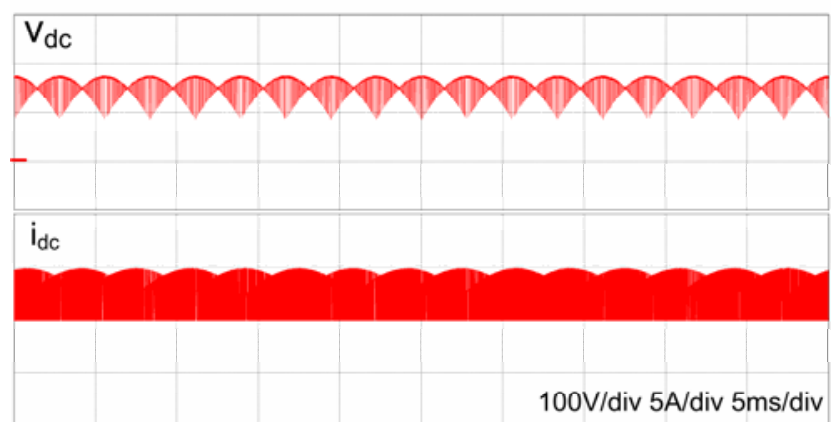

Fig. 8. The simulation results of dc-link voltage and dc-link current.

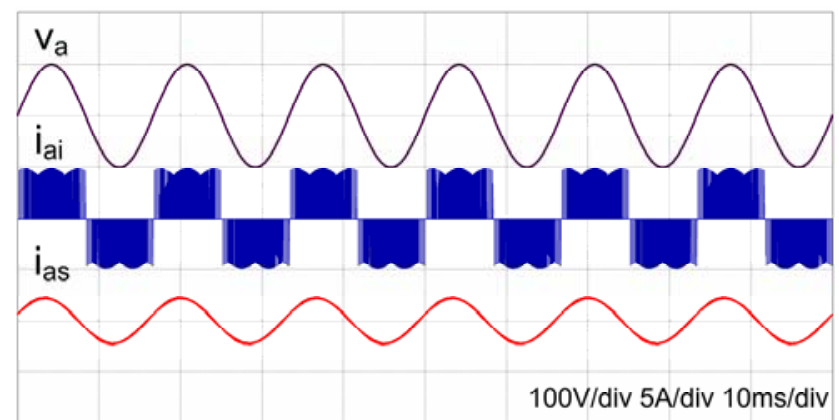

Fig. 9. The simulation results of phase input voltage, input current of IMC and phase current of power supply.

\section{Simulation Results}

Simulation are carried out with Psim 9.0 software to verify the proposed carrier-based PWM method. The system is simulated with the parameters as follows:

1) A three-phase input voltage $100 \mathrm{~V} / 60 \mathrm{~Hz}$ (line-to-neutral voltage).

2) The $L C$ input filter parameter is designed with $L=1.4 \mathrm{mH}$ and $C=22.5 \mu \mathrm{F}$.

3) The three-phase load is an inductive load with $R=12 \Omega$ and $L=10 \mathrm{mH}$.

4) The load operates with a transfer voltage ratio of 0.75 $(q=0.75)$ and a frequency of $50 \mathrm{~Hz}\left(f_{\text {out }}=50 \mathrm{~Hz}\right)$.

5) The frequency of the symmetrical triangular carrier signal is $10 \mathrm{kHz}$.

Fig. 8 shows the dc-link voltage $\left(V_{d c}\right)$ and the dc-link current $\left(i_{d c}\right)$ of the IMC. In the rectifier stage control, the zero vectors are eliminated. Therefore, the dc-link voltage does not reach to zero. The dc-link voltage is formed by the two line-to-line input voltages. Fig. 9 shows the input waveforms of the IMC. From Fig. 9, it can be seen that the input current of the IMC $\left(i_{a i}\right)$ is in phase with the phase input voltage $\left(v_{a}\right)$. The presence of the input filter in the input side causes a slight displacement angle between the main input current $\left(i_{a s}\right)$ and the input voltage. The simulation results shown in Fig. 10 are the output waveforms of the IMC. In Fig. 10, the upper 


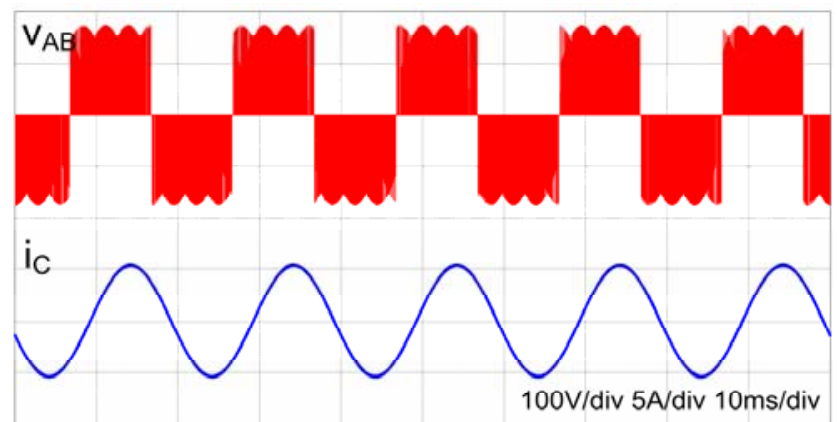

Fig. 10. The simulation results of of line-to-line output voltage and phase output current.

trace $\left(v_{A B}\right)$ is line-to-line output voltage and the lower trace $\left(i_{C}\right)$ is the phase output current. It can be seen that the output current is a pure sinusoidal waveform. From these results, an IMC with the proposed carrier-based PWM method provides sinusoidal input and output currents.

\section{EXPERIMENTAL RESULTS}

To validate the proposed theories and simulation, the IMC topology was built in the laboratory. Experimental tests were carried out using a three-phase power supply $(60 \mathrm{~Hz} / 100 \mathrm{~V})$, a three-phase inductive load $(R=12 \Omega$, $L=10 \mathrm{mH})$, and an input filter with a Y connection $(L=1.4 \mathrm{mH}$, $C=22.5 \mu \mathrm{F}$ ) which are identical to the simulation parameters. A photograph of the experiment equipment is shown in Fig. 11. The control system is implemented by a 32-bit DSP TMS320F28335 operating with a clock of $150 \mathrm{MHz}$ and a complex programmable logic device (CPLD) EPM7128SLC84-15. The power switches IGBTs G4PF50WD - have been used to implement the power circuit in the rectifier and inverter stages.

Fig. 12 shows the experimental PWM signals for the modulated switch $\left(S_{b n}\right)$ of the rectifier stage and the three upper switches $\left(S_{A}, S_{B}\right.$, and $\left.S_{C}\right)$ of the inverter stage. It can be seen that the switch $S_{b n}$ changes the state from high to low or from low to high at the time when the inverter stage is switched into a free-wheeling stage. Therefore, the zero dc-link current commutation in the rectifier stage is guaranteed. It is evident that the switching frequency of the rectifier stage is the same frequency as the carrier signal $(10 \mathrm{kHz})$, while the switching frequency in the inverter stage is twice that of the rectifier stage.

Fig. 13 shows the experimental PWM signals for the six bidirectional switches in the rectifier stage. It can be observed that, in each sector, one of the switches is always in the high state and that two of the switches are modulated. For example, in sector 1 , the switch $S_{a p}$ is in the high state and the two switches $S_{b n}$ and $S_{c n}$ are modulated to generate a dc-link

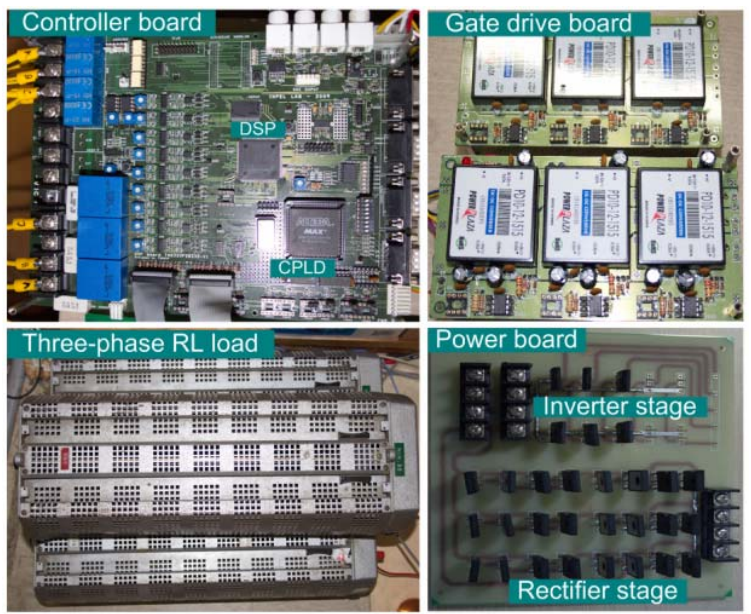

Fig. 11. Photograph of the experimental setup.

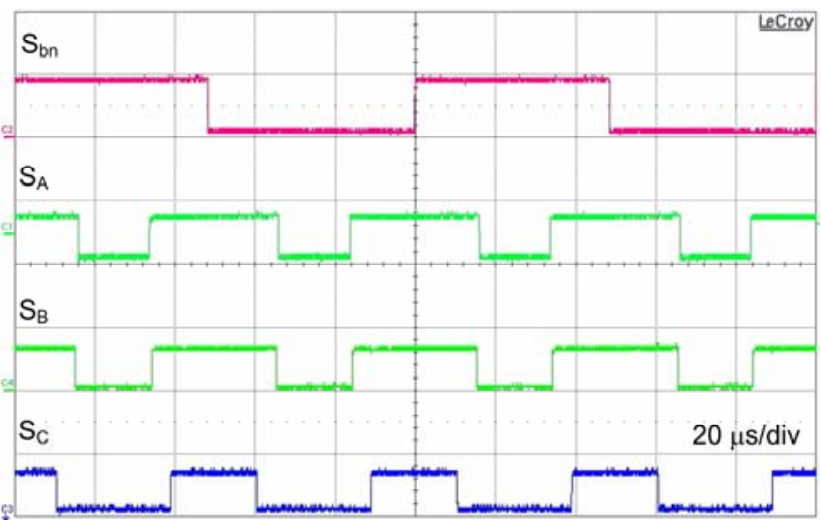

Fig. 12. Experimental PWM signals for the modulated switch in rectifier stage $\left(\mathrm{S}_{\mathrm{bn}}\right)$ and three upper switches in the inverter stage $\left(\mathrm{S}_{\mathrm{A}}, \mathrm{S}_{\mathrm{B}}, \mathrm{S}_{\mathrm{C}}\right)$.

voltage with values $v_{a b}$ and $v_{a c}$. The other switches are all in the low state.

The waveforms of the dc-link voltage and dc-link current are shown in Fig. 14. It can be seen that the dc-link voltage is switched to the maximum and medium line-to-line input voltage in order to achieve the maximum average dc-link voltage. The dc-link voltage has no zero value due to the lack of zero vectors in the rectifier stage control. The dc-link current reaches to the zero value when the inverter stage operates at the zero vectors $\left(V_{0}, V_{7}\right)$ and at this time, the commutation in rectifier stage occurs.

The input current of the IMC $\left(i_{a i}\right)$, the input current of the power supply $\left(i_{a s}\right)$ and its corresponding phase voltage $\left(v_{a}\right)$ are shown in Fig. 15. As expected, the input current of the IMC is in phase with the input voltage. There is a displacement angle between the input voltage and the input current of the power supply due to the input filter. The input current of the power supply is a sinusoidal waveform despite the fact that the input current of the IMC is discontinuous. However, there is the presence of slight oscillatory ripple in the input current of the power supply which is due to a 


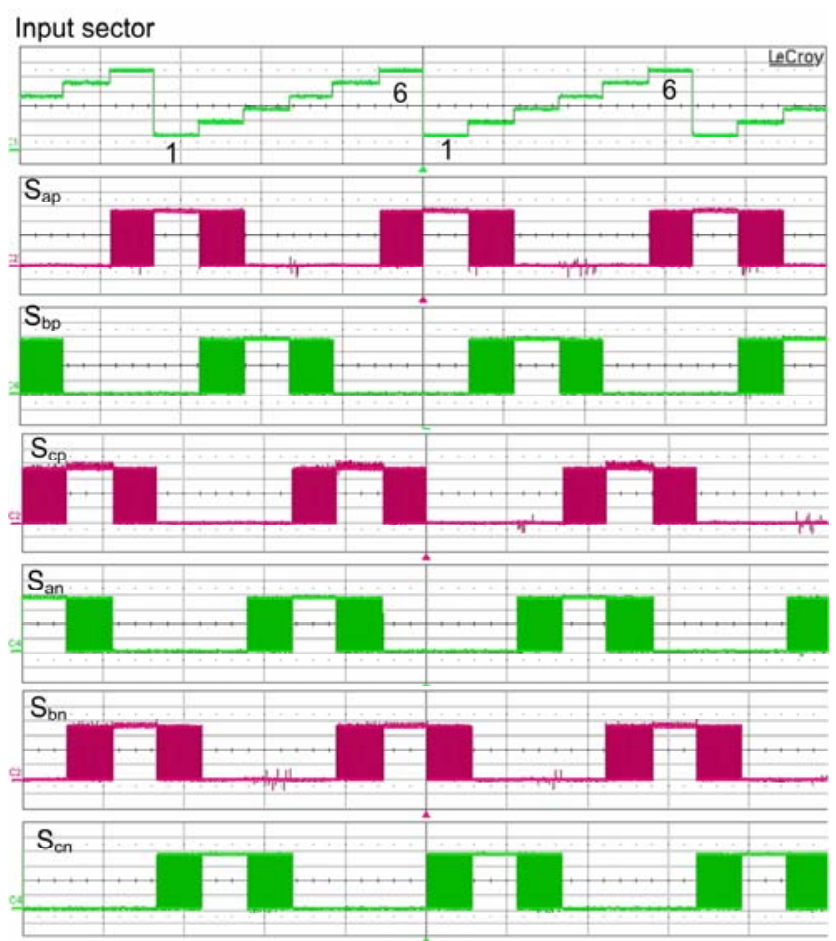

Fig. 13. The experimental PWM signals for six bidirectional switches of rectifier stage.

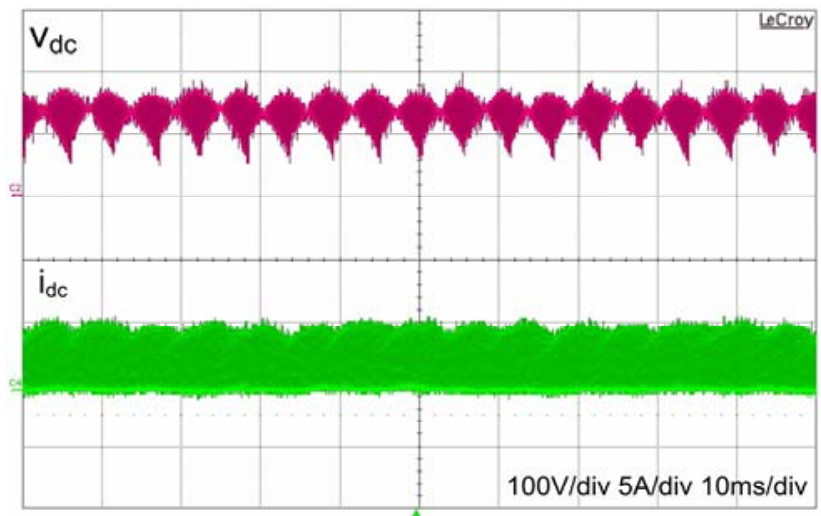

Fig. 14. The experimental results of dc-link voltage and dc-link current.

hardware limitation.

The line-to-line output voltage $\left(V_{A B}\right)$ and the phase output current $\left(i_{C}\right)$ are shown in Fig. 16. It can be observed that the peak line-to-line output voltage is the same as the line-to-line input voltage $(173 \mathrm{~V})$. From the output current waveform, it can be seen that a good sinusoidal waveform is obtained.

From the experimental results, it can be seen that the performance of the IMC such as the near unity input power factor and the sinusoidal waveforms for both the input and output currents can be achieved by using the proposed method. The experimental results are nearly identical to the simulation results.

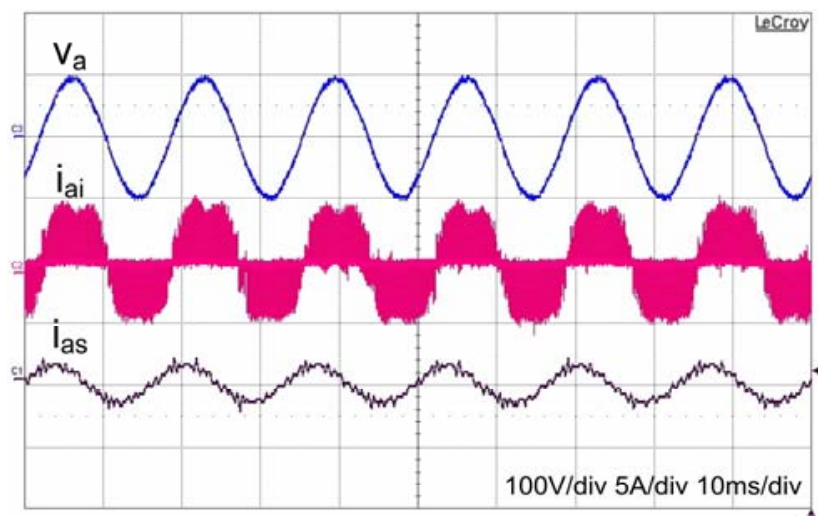

Fig. 15. The experimental results of phase input voltage, input current of IMC and phase current of power supply.

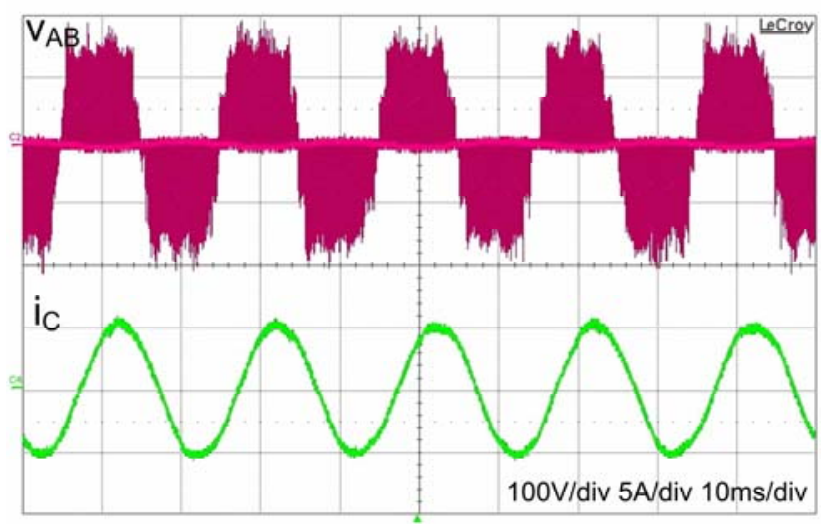

Fig. 16. The experimental results of line-to-line output voltage and phase output current.

\section{CONCLUSIONS}

A carrier-based modulation scheme for the IMC is developed in this paper. Because only one symmetrical triangular carrier signal is used to generate the pulses for both the rectifier and inverter stage control, it can be implemented easily with simpler hardware and software than the conventional SVPWM. The proposed method overcomes some of the drawbacks of the SVPWM such as the difficulty in detecting the position of the reference input current vector and the reference output voltage vector, the burden of calculating the duty cycles of the effective vectors in the rectifier and the inverter stage, and the complexity involved in combining the switching state of rectifier and inverter stages for making the switching pattern of the IMC. The proposed method has been verified by a numerical simulation. In addition, an experimental hardware setup has been built and the proposed modulation has been implemented by using a DSP and a CPLD. The experimental results validate the theoretical analysis and simulation results. 


\section{ACKNOWLEDGMENT}

"This work was partly supported by the NRF grant funded by the Korea government (MEST) (No. 2010-0025483) and University of Ulsan, School of Excellence in Electrical Engineering.

\section{REFERENCES}

[1] A. Alesina and M.G.B. Venturini "Solid-state power conversion: A Fourier analysis approach to generalized transformer synthesis," IEEE Trans. Circuits and Syst., Vol.28, No.4, pp. 319- 330, Apr. 1981.

[2] J. W. Kolar, T. Friedli, J. Rodriguez, and P.W. Wheeler, "Review of three-phase PWM AC-AC converter topologies," IEEE Trans. Ind. Electron., Vol.58, No.11, pp. 4988-5006, Nov. 2011.

[3] P. W. Wheeler, J. Rodriguez, J. C. Clare, L. Empringham, and A. Weinstein, "Matrix converters: a technology review," IEEE Trans. Ind. Electron., Vol.49, No.2, pp. 276-288, Apr. 2002.

[4] T. F. Podlesak, D. C. Katsis, P. W. Wheeler, J. C. Clare, L. Empringham, and M. Bland, "A 150-kVA vector-controlled matrix converter induction motor drive," IEEE Trans. Ind. Appl., Vol. 41, No. 3, pp. 841-847, May/Jun. 2005.

[5] C. Klumpner and F. Blaabjerg, "Two stage direct power converters: an alternative to the matrix converter," in Proc. IEE Seminar on Matrix Converters, pp. 7/1- 7/9, [Digest No. 2003/10100]. Apr. 2003.

[6] J. W. Kolar, F. Schafmeister, S. D. Round, and H. Ertl, "Novel three-phase AC-AC sparse matrix converters," IEEE Trans. Power Electron., Vol. 22, No. 5, pp. 1649-1661, Sep. 2007.

[7] C. Klumpner and F. Blaabjerg, "Modulation method for a multiple drive system based on a two-stage direct power conversion topology with reduced input current ripple," IEEE Trans. Power Electron., Vol. 20, No. 4, pp. 922- 929, Jul. 2005.

[8] R. Pena, R. Cardenas, E. Reyes, J. Clare, and P. Wheeler, "A Topology for multiple generation system with doubly fed induction machines and indirect matrix converter," IEEE Trans. Ind. Electron., Vol. 56, No. 10, pp. 4181-4193, Oct. 2009.

[9] T. Wijekoon, C. Klumpner, P. Zanchetta, and P. W. Wheeler, "Implementation of a hybrid AC-AC direct power converter with unity voltage transfer," IEEE Trans. Power Electron., Vol. 23, No. 4, pp. 1918-1926, Jul. 2008.

[10] M. Milanovic and B. Dobaj, "Unity input displacement factor correction principle for direct $\mathrm{AC}$ to $\mathrm{AC}$ matrix converters based on modulation strategy," IEEE Trans. Circuits Syst. I, Fundam. Theory Appl., Vol. 47, No. 2, pp. 221-230, Feb. 2000.

[11] L. Helle, K. B. Larsen, A. H. Jorgensen, S. Munk-Nielsen, and F. Blaabjerg, "Evaluation of modulation schemes for three-phase to three-phase matrix converters," IEEE Trans. Ind. Electron., Vol. 51, No. 1, pp. 158-171, Feb. 2004.

[12] Y. D. Yoon and S. K. Sul; "Carrier-based modulation technique for matrix converter," IEEE Trans. Power Electron., Vol. 21, No. 6, pp. 1691-1703, Nov. 2006.

[13] Y. Li, N. S. Choi, and B. M. Han, "DDPWM based control of matrix convertes," Journal of Power Electronics, Vol. 9,
No. 4, pp. 535-543, Jul. 2009.

[14] S. M Kim, Y. D. Yoon, and S. K. Sul, "Pulsewidth modulation method of matrix converter for reducing output current ripple," IEEE Trans. Power Electron., Vol. 25, No. 10, pp. 2620-2629, Oct. 2010.

[15] H. M. Nguyen, H. H. Lee, and T. W. Chun, "Input power factor compensation algorithms using a new direct-svm method for matrix converter," IEEE Trans. Ind. Electron., Vol. 58, No. 1, pp. 232-243, Jan. 2011.

[16] P. Correa, J. Rodriguez, M. Rivera, J. R. Espinoza, and J. W. Kolar, "Predictive control of an indirect matrix converter," IEEE Trans. Ind. Electron., Vol. 56, No. 6, pp. 1847-1853, Jun. 2009.

[17] J. Rodriguez, M. Rivera, J. W. Kolar, and P. W. Wheeler "A review of control and modulation methods for matrix converters," IEEE Trans. Ind. Electron., Vol. 59, No. 1, pp. 58-70, Jan. 2012.

[18] M. Hamouda, H. F. Blanchette, K. Al-Haddad, and F. Fnaiech, "An efficient DSP-FPGA-Based real-time implementation method of SVM algorithms for an indirect matrix converter," IEEE Trans. Ind. Electron., Vol. 58, No. 11, pp. 5024-5031, Nov. 2011.

[19] R. Pena, R. Cardenas, E. Reyes, J. Clare, and P. Wheeler, "Control of a doubly fed induction generator via an indirect matrix converter with changing DC voltage," IEEE Trans. Ind. Electron., Vol. 58, No. 10, pp. 4664-4674, Oct. 2011.

[20] L. Wei and T. A. Lipo, "A novel matrix converter topology with simple commutation," in Record of the IEEE Industry Applications Conference, Chicago, IL, USA, pp. 1749-1754, 2011.

[21] T. D. Nguyen and H. H. Lee "Modulation strategies to reduce common-mode voltage for indirect matrix converters," IEEE Trans. Ind. Electron., Vol. 59, №. 1, pp. 129-140, Jan. 2012.

[22] P. C. Loh, R. Rong, F. Blaabjerg, and P. Wang, "Digital carrier modulation and sampling issues of matrix converters," IEEE Trans. Power Electron., Vol. 24, No. 7, pp. 1690-1700, Jul. 2009.

[23] B. Wang and G. Venkataramanan, "A carrier based PWM algorithm for indirect matrix converters," in Proc. PESC, pp. 1-8, 2006.

[24] H. W. Van der Broeck, H. C. Skudelny, and G. V. Stanke, "Analysis and realization of a pulsewidth modulator based on voltage space vectors," IEEE Trans. Ind. Appl., Vol. 24, No. 1, pp. 142-150, Jan./Feb. 1988.

[25] V. Blasko, "Analysis of a hybrid PWM based on modified space-vector and triangle-comparison methods," IEEE Trans. Ind. Appl., Vol. 33, No. 3, pp. 756-764, May/Jun. 1997.

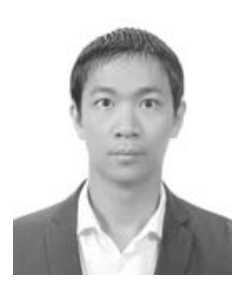

Dinh-Tuyen Nguyen was born in Binh Dinh Province, Vietnam, in 1982. He received his B.S. in Electrical Engineering from the University of Technology, Hochiminh City, Vietnam, in 2004. Currently, he is an M.S./Ph.D. student at the University of Ulsan, Ulsan, Korea. His research interests include power electronics, electrical machine drives, low cost inverters, renewable energy, and especially matrix converters. 
Hong-Hee Lee is a Professor in the School of Electrical Engineering, University of Ulsan, Ulsan, Korea. He is also the Director of the Network-based Research Center (NARC). He received his B.S., M.S., and Ph.D. in Electrical Engineering from Seoul National University, Seoul, Korea, in 1980, 1982, and 1990, respectively. His current research interests include power electronics, network-based motor control, and control networks. He is a member of the Institute of Electrical and Electronics Engineers (IEEE), the Korean Institute of Power Electronics (KIPE), the Korean Institute of Electrical Engineers (KIEE), and the Institute of Control, Automation, and Systems Engineers (ICASE).

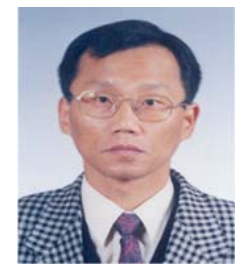

Tae-Won Chun was born in Korea in 1959. He received his B.S. in Electrical Engineering from Pusan National University, Pusan, Korea, in 1981, and his M.S. and Ph.D. in Electrical Engineering from Seoul National University, Seoul, Korea, in 1983 and 1987, respectively. Since 1986, he has been a Faculty Member in the Department of Electrical Engineering, University of Ulsan, Ulsan, Korea, where he is currently a Full Professor. His current research interests include the control of electrical machines, power converter circuits, and industrial applications. 